\title{
With little research training, geriatricians pick clinic over the lab
}

Raj Shah trained as most good geriatricians do in the US: he sweated his way through medical school, honed his skills in a general residency, wrapped up with a geriatrics fellowship and then entered practice treating the elderly at a major medical center.

It was while attending patient after patient at the Rush Alzheimer's Disease Center in Chicago (where Shah now serves as medical director of the memory clinic) that a limitation in his training dawned on him. Shah began to notice non-neurologic risk factors, such as high blood pressure and anemia, that he believed might be treated to reduce disability in old age. "But," Shah says, "we didn't have someone who could take that information about a modifiable risk factor and translate it to a clinical trial"himself included.

Shah is not the first to lament the lack of personnel qualified in clinical research for the elderly. "There is a huge need to train people," says Raymond Yung, co-director of the Geriatrics Center at the University of Michigan in Ann Arbor. "Right now, the biology of aging is advancing so fast, there are so many opportunities and possibilities, but we're not finding the people to do that work."

Marie Bernard, deputy director of the National Institute on Aging (NIA), a division of the US National Institutes of Health (NIH) located in Bethesda, Maryland, agrees. "The people who would likely do this sort of research are academic geriatricians, and their numbers are declining."

This problem is even more pronounced for physicians who want to take observations from the bedside back to the bench for further investigations in the laboratory. There are currently around 7,000 boardcertified geriatricians in the US. According to James Kirkland, director of the Mayo Clinic's Robert and Arlene Kogod Center on Aging in Rochester, Minnesota, only around a dozen have basic science RO1 grants-the mainstay of funding for investigator-initiated biomedical research projects from the NIH. "There are very few geriatricians who have basic science knowledge, and that makes doing translational and preclinical studies difficult," Kirkland says.

With no one to test his ideas, Shah took matters into his own hands by embarking on a self-taught path to clinical research: he read everything he could about clinical trial design, served on Rush's institutional review board, became a certified principal investigator and volunteered as a part of the clinical team on colleagues' trials.

Shah's story, however, is rare. Most

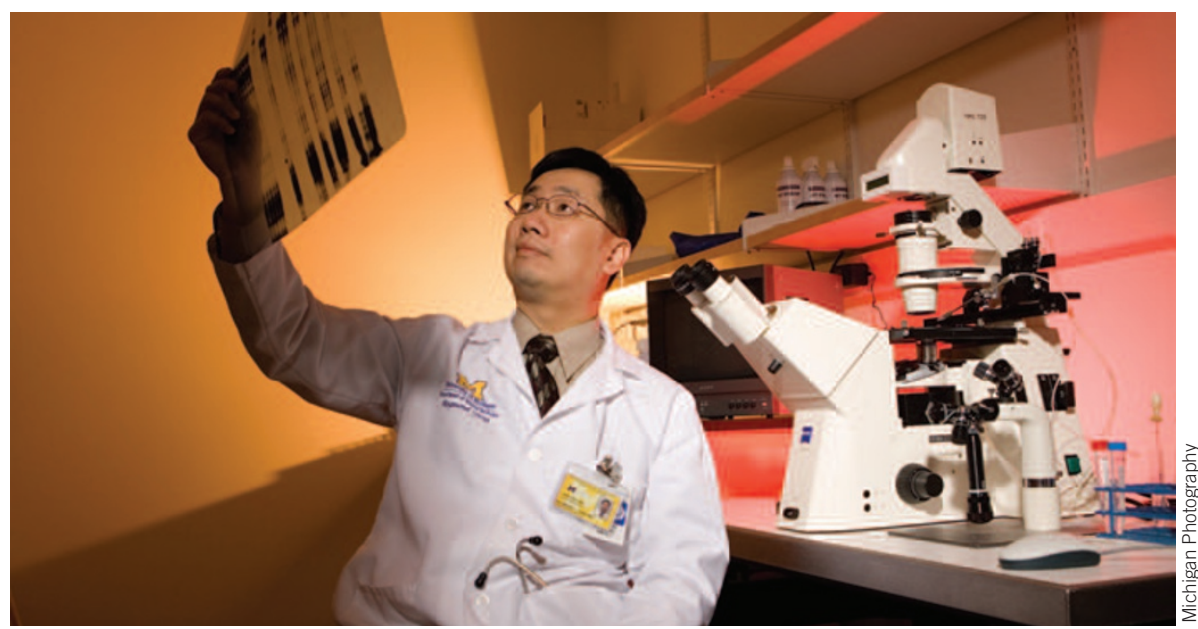

Charting a new course: Geriatricians like Raymong Yung (pictured) see the need to pursue research.

geriatricians do not seek out research experience, nor are they exposed to research while in clinical training. As a result, few geriatricians even know how to ask proper research questions, and academic gerontology labs have no clinically oriented research fellows with whom to staff their research teams. Physicians with expertise in cardiology, nephrology and other specialties often fill in the gap. But there's a holistic appreciation of the aging process-and the associated problems that prevent independent living - that geriatricians gain from routinely treating the elderly. This intimate knowledge, experts say, is currently missing from the research enterprise.

\section{Follow the money}

The foremost reason for the dearth of physician-scientists in geriatrics is a recent change in the training procedure for the subspecialty. Geriatrics used to involve a twoyear fellowship-a year of intense clinical work followed by a year of research. But in the mid1990s, the Accreditation Council for Graduate Medical Education, the body responsible for overseeing graduate medical training programs in the US, reduced its geriatrics subspecialty requirement from two years to one. "While the intention was to increase the number of geriatricians in the country, it made it harder to train academic geriatricians," says Yung, who got his research training during a three-year rheumatology fellowship, not during his oneyear geriatrics fellowship in 1996.

Today, most MDs complete that single yearall clinical work - and move right into lucrative practice, where they can start paying off medical school loans. According to the American Geriatrics Society, the median salary for a geriatrician in private practice was $\$ 183,523$ in
2010, the last year for which data are available. It's a far more attractive choice than a low-paying research fellowship followed by many more years of work before even the chance of winning a coveted $\mathrm{RO} 1$ grant.

There are some proposed solutions to improve this personnel shortfall. Foremost is working with private funders to find the money to support MDs who do express an interest in research. The Paul Beeson Career Development Award in Aging and the GEMSSTAR (Grants for Early Medical/ Surgical Subspecialists' Transition to Aging Research) programs are both supported by the NIA together with philanthropic groups, including the John A. Hartford Foundation, a New York-based nonprofit committed to the well-being of older adults. Organizations such as the Ellison Medical Foundation and the Glenn Foundation For Medical Research, both dedicated to research on the mechanisms of aging, also fund research awards for students, postdocs and more established investigators.

Overall, training programs need to either start offering salaries that can match what fellows will make in practice or start attracting nonAmerican MDs eager to do research in the US, suggests Nir Barzilai, director of the Institute for Aging Research at the Albert Einstein College of Medicine in New York. "It's easy to find those people [non-Americans], but I cannot pay them from my training grants," he says. "There are lots of limits on supporting foreign graduates.”

It's a hard sell in a time of fiscal constraint, but most experts agree: if the money were there, the ranks of physician-scientists in geriatrics would swell. Then, translational research would no longer play second fiddle to clinical practice in the perennial march of aging.

Megan Scudellari 